\title{
The Effect of Methyl Linoleate Hydroperoxides and Radical Initiator 2,2'-Azobis (2-Amidinopropane) Dihydrochloride on Antibody Production by Mouse Spleen Cells
}

\author{
Motoko OARAdA, ${ }^{*}$ Nobuyuki Kurita and Makoto MiYaJI \\ Research Center for Pathogenic Fungi and Microbial Toxicoses, \\ Chiba University, Chuo-ku, Chiba, Chiba 260, Japan
}

(Received December 10, 1996)

\begin{abstract}
Summary Methyl linoleate hydroperoxides (MLHPO) and 2,2'-azobis(2-amidinopropane)dihydrochloride (AAPH), a widely used free radical initiator, were examined for effects on antibody production by spleen cells using plaque-forming cell response against sheep red blood cells (SRBC). The in vitro primary antibody response was enhanced in the presence of MLHPO at a concentration range of $2-20 \mu \mathrm{M}$ or AAPH at 0.1 $\mu \mathrm{M}$, but was suppressed with higher concentrations of these compounds. In the in vitro secondary antibody response, both MLHPO and AAPH failed to increase plaque-forming cell response above that of the control culture. Following the oral administration of MLHPO $(2.29 \mathrm{~g} / \mathrm{kg})$ four times to mice, in vivo primary plaque-forming cell response was significantly suppressed. After, a single intraperitoneal injection of AAPH (60 $\mathrm{mg} / \mathrm{kg}$ ) to mice, in vivo primary plaque-forming cell response was also suppressed. These findings suggest that primary antibody response can be affected by lipid hydroperoxides and oxygen radicals in vivo.
\end{abstract}

Key Words lipid peroxide, oxygen radicals, antibody production, plaqueforming cells

The relationship between nutrition and immunity has received much attention. For example, the effects of single nutrients such as vitamins, lipids and minerals on immune functions have been studied (1-5). It should also be of importance to elucidate the relationships between toxic food components and immune functions. We have been studying the absorption, distribution and pathological effects of lipid hydroperoxides, the substances produced in the oxidation of polyunsaturated fatty acids in lipids. It was found that they are absorbed into animals via the digestive tract and exert significant effects on lymphoid tissues such as the thymus, spleen and Peyer's patches (6-8). The DNA synthesis of thymic lymphocytes was depressed after long-term feeding of mice with slightly autoxidized soybean oil (9). Thymic

\footnotetext{
* To whom correspondence should be addressed.
} 
lymphocytes and splenic lymphoblasts are markedly affected by exogenous lipid hydroperoxides as compared to non-blastotransformed lymphocytes (10).

In this study, we examined lipid hydroperoxides for in vitro and in vivo effects on the antibody response of mouse spleen cells using methyl linoleate hydroperoxides (MLHPO). In addition, a well-known free radical initiator, 2,2' -azobis(2-amidinopropane) dihydrochloride (AAPH), was also examined for its effects.

\section{MATERIALS AND METHODS}

Materials. Male C57BL/6 mice were purchased from Charles River Japan (Atsugi, Japan). All mice used for experiments were 12-14 weeks of age.

Sheep red blood cells (SRBC) were obtained from Nippon Bio-Test Laboratories (Tokyo, Japan). Before using as the antigen, SRBC were washed four times with phosphate buffered saline.

MLHPO were prepared as described previously (6). Purified MLHPO have a peroxide value $(\mathrm{PV})$ of $6,085 \mathrm{meq} / \mathrm{kg}$. MLHPO and methyl linoleate $(\mathrm{ML} ; \mathrm{PV}=$ $0.6 \mathrm{meq} / \mathrm{kg}$ ) were dissolved in dimethyl sulfoxide (DMSO) individually, and then suspended in complete medium consisting of RPMI 1640 medium, 20\% (v/v) fetal calf serum (Gibco BRL Life Technologies, NY, USA, Lot No. 35P1056), 2 mM L-glutamine (Gibco), $50 \mu \mathrm{M}$ 2-mercaptoethanol (Wako Pure Chemical Ind., Osaka, Japan), $12.5 \mathrm{~mm}$ HEPES buffer solution (Gibco), $100 \mu \mathrm{g} / \mathrm{mL}$ streptomycin and 100 $\mathrm{U} / \mathrm{mL}$ penicillin.

AAPH was obtained from Wako Pure Chemical.

Primary antibody response in vitro. Single-cell suspensions of spleen cells were prepared by teasing the spleen with forceps in the complete medium. Spleen cells were washed twice with complete medium and then suspended at a density of $1 \times$ $10^{8}$ cells $/ \mathrm{mL}$ of complete medium. Nine hundred and fifty microliters of complete medium, $50 \mu \mathrm{L}$ of SRBC suspension $(1 \%(\mathrm{v} / \mathrm{v})$ in complete medium) and $100 \mu \mathrm{L}$ of spleen cell suspension $\left(1 \times 10^{8} \mathrm{cell} / \mathrm{mL}\right)$ were dispensed in each tissue culture dish ( $35 \times 10 \mathrm{~mm}$ style, NUNC, Roskilde, Denmark), and $100 \mu \mathrm{L}$ of DMSO, MLHPO or ML solution was added to each dish. The final concentration of DMSO in cultures was $0.00008-0.2 \%(\mathrm{v} / \mathrm{v})$. MLHPO and ML were individually added to cultures to final concentrations of $0.02-50 \mu \mathrm{M}$ (DMSO; $0.00008-0.2 \%(\mathrm{v} / \mathrm{v})$ ). Cultures were incubated for 5 or 6 days at $37^{\circ} \mathrm{C}$ in $5 \% \mathrm{CO}_{2}-95 \%$ air. Culture dishes were shaken gently for $1 \mathrm{~min}$ every $12 \mathrm{~h}$. After culturing, the cells were scraped off from the dishes with a rubber policeman using a cold complete medium, and then washed and resuspended in RPMI 1640 medium containing 5\% (v/v) fetal calf serum, $2 \mathrm{mM}$ L-glutamine and $12.5 \mathrm{~mm}$ HEPES buffer. Cells were assayed for direct anti-SRBC plaque-forming cells using the microscope slide adaptation of the procedure of Cunningham (11).

Spleen cells were incubated in the presence of AAPH for 5 or 6 days under the same conditions as for incubation with MLHPO. AAPH was added to cultures to a final concentration range of $0.01-100 \mu \mathrm{M}$. After incubation, cells were assayed 
for direct anti-SRBC plaque-forming cells in the same manner as described above.

Secondary antibody response in vitro. The mice were injected intraperitoneally with $250 \mu \mathrm{L}$ SRBC suspensions (10\% (v/v) in $0.9 \%-\mathrm{NaCl}$ solution). Three days after the administration of SRBC, single-cell suspensions of spleen cells were prepared at a density of $7.5 \times 10^{7}$ cells $/ \mathrm{mL}$ complete medium. $7.5 \times 10^{6}$ cells were incubated in the presence of MLHPO or AAPH for 4 or 5 days under the same conditions as for the primary antibody response, and then assayed for direct anti-SRBC plaque-forming cells.

Primary antibody response in vivo. Mice (12 weeks old, each group consisting of four mice) were orally given $2.29 \mathrm{~g} / \mathrm{kg}$ of ML or MLHPO four times at $48 \mathrm{~h}$ intervals via a stomach tube. On the day of the last administration of ML or MLHPO, mice were given a single intraperitoneal injection of $250 \mu \mathrm{L}$ SRBC suspension. Five days after SRBC injection, single-cell suspensions were separately prepared from individual mouse spleens and assayed for direct anti-SRBC plaqueforming cells.

Mice were intraperitoneally injected once with 40 or $60 \mathrm{mg} / \mathrm{kg}$ of AAPH and then injected with SRBC suspension the day after AAPH administration. Five days after SRBC injection, cells were prepared and assayed for direct anti-SRBC plaque-forming cells.

\section{RESULTS}

\section{Primary antibody response in vitro}

Plaque-forming cell response was assayed as a measure of the antibody response of spleen cells. The peak of the response was observed after 5 or 6 days of culturing. Figure 1 shows the number of plaque-forming cells after 5 days of culturing. Since DMSO was used as the solvent for ML and MLHPO, we first clarified whether DMSO had any effect on plaque-forming cell response. DMSO $(0.008-0.2 \%(\mathrm{v} / \mathrm{v}))$ decreased the number of plaque-forming cells after incubation. Although the number of plaque-forming cells in the ML $(2-50 \mu \mathrm{M})$-treated cells also decreased, there was no significant difference between the number of plaqueforming cells in DMSO- and ML-treated cells, indicating that the primary plaqueforming cell response was not affected by ML. The number of plaque-forming cells was significantly increased in 2 and $20 \mu \mathrm{M}$ MLHPO-treated spleen cells as compared to that of ML-treated control cells. In contrast, the treatment of spleen cells with $50 \mu \mathrm{M}$ MLHPO almost completely eliminated all plaque-forming cells. These results were also obtained at day 6 of incubation with MLHPO (data not shown).

Although AAPH is not a natural compound, it has been widely used in order to generate free radicals in culture medium and animals by its thermal decomposition (12-15). Figure 2 presents the effect of AAPH on plaque-forming cell response after 6 days incubation. In the presence of $100 \mu \mathrm{M} \mathrm{AAPH,} \mathrm{the} \mathrm{number} \mathrm{of}$ plaque-forming cells was significantly decreased as compared to that of the untreated control cells. In contrast, a concentration as low as $0.1 \mu \mathrm{M} \mathrm{AAPH} \mathrm{was}$ 


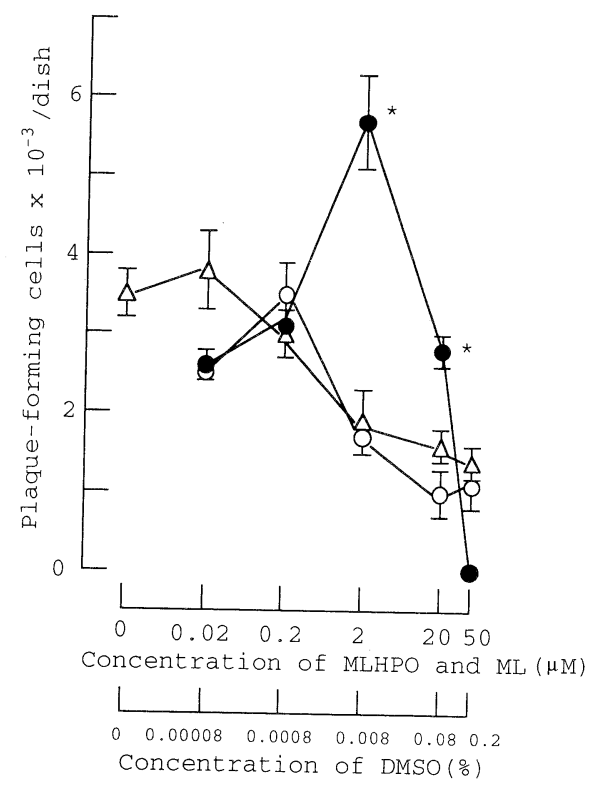

Fig. 1. Effect of MLHPO on in vitro primary plaque-forming cell response against the SRBC of spleen cells. Spleen cells were cultured in the presence of MLHPO or ML. ML and MLHPO were dissolved in DMSO and added to the cultures. Spleen cells treated with DMSO alone $(\triangle)$, with ML $(\bigcirc)$ and with MLHPO (๑). Values represent mean $\pm \mathrm{SE}$ of triplicate cultures. Significant difference from control (ML-treated spleen cell cultures) was determined by Student's $t$-test $\left({ }^{*} p<0.01\right)$.

responsible for a significant increase in the number of plaque-forming cells.

Secondary antibody response in vitro

The peak of the in vitro secondary plaque-forming cell response was observed after 4 or 5 days of culturing. At day 4 of incubation, ML exhibited no significant effect on the number of plaque-forming cells, and MLHPO $(0.02-20 \mu \mathrm{M})$ also exerted no significant effect on the number of plaque-forming cells as compared to that of the ML-treated control cells (Fig. 3). These results were also obtained at day 5 of incubation with MLHPO (data not shown).

Figure 4 shows the effect of AAPH on plaque-forming cell response at day 5 of incubation. AAPH $(100 \mu \mathrm{M})$ significantly decreased the number of plaque-forming cells compared to the untreated control cells. Unlike the primary plaque-forming cell response (Figs. 1, 2), MLHPO and AAPH, at any concentration examined, failed to increase the number of plaque-forming cells above that of the control culture. 


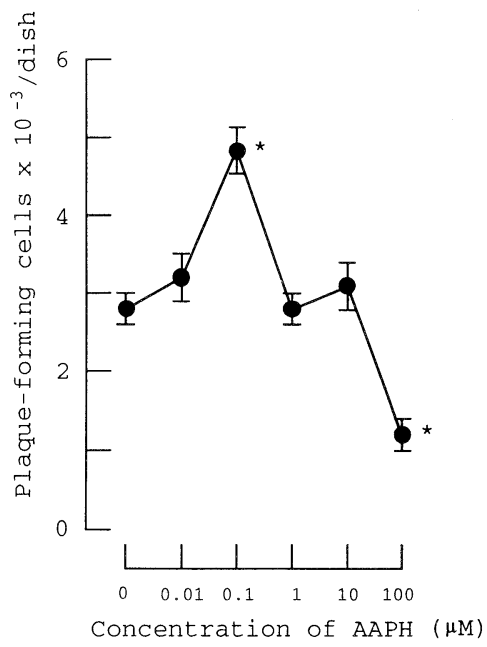

Fig. 2. Effect of AAPH on in vitro primary plaque-forming cell response against SRBC of spleen cells. Spleen cells were cultured in the presence of AAPH. Values represent mean $\pm S E$ of triplicate cultures. Significant difference from control (untreated spleen cell cultures) was determined by Student's $t$-test $\left({ }^{*} p<\right.$ $0.01)$.

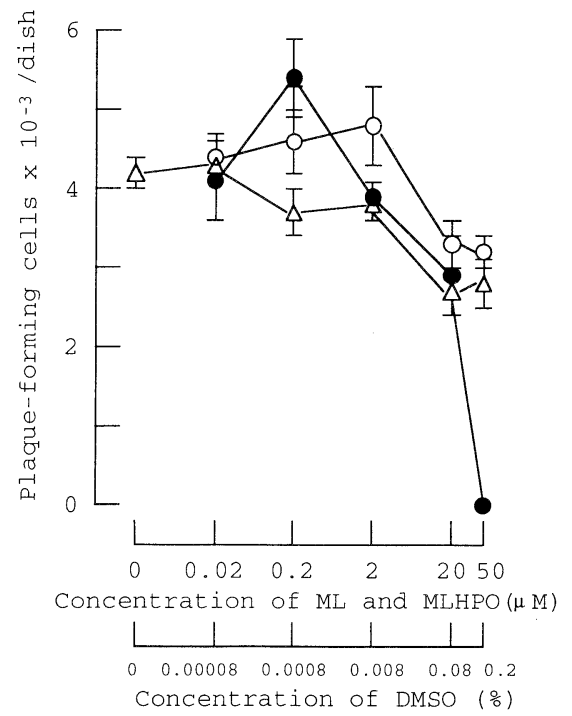

Fig. 3. Effect of MLHPO on in vitro secondary plaque-forming cell response against the SRBC of spleen cells. Spleen cells were cultured in the presence of MLHPO or ML. ML and MLHPO were dissolved in DMSO and added to the cultures. Spleen cells treated with DMSO alone $(\triangle)$, with ML $(\bigcirc)$ and with MLHPO (O). Values represent mean \pm SE of triplicate cultures.

Vol 43, No 3, 1997 


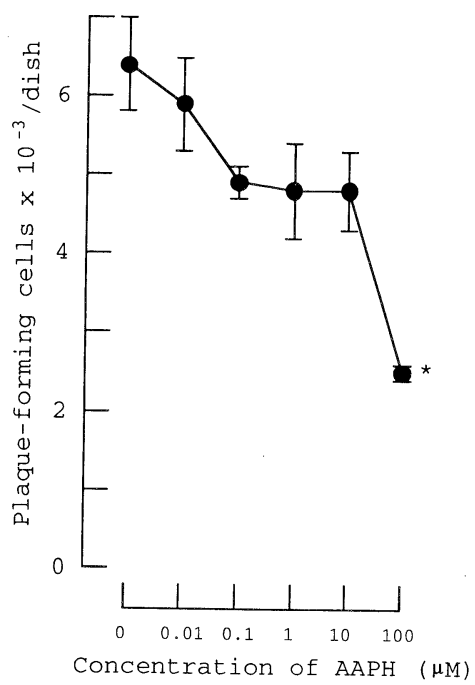

Fig. 4. Effect of AAPH on in vitro secondary plaque-forming cell response against the SRBC of spleen cells. Spleen cells were cultured in the presence of AAPH. Values represent mean $\pm S E$ of triplicate cultures. Significant difference from control (untreated spleen cell cultures) was determined by Student's $t$-test $\left({ }^{*} p<\right.$ $0.01)$.

\section{Primary antibody response in vivo}

Dose amounts of MLHPO and AAPH into mice were determined from previous studies $(7,9,14)$. Mice were treated with amounts of MLHPO or AAPH which cause no significant morphological effect on an animal's organs, such as liver, spleen and thymus, when examined in a conventional histopathological manner. The number of plaque-forming cells in MLHPO-treated mice was significantly decreased as compared to that of the ML-treated control mice at day 5 after SRBC injection (Fig. 5(a)). The number of plaque-forming cells in $60 \mathrm{mg} / \mathrm{kg} \mathrm{AAPH}$ treated mice was significantly decreased as compared to that of the untreated control mice at day 5 after SRBC injection, although there was no significant difference in the number of plaque-forming cells between the untreated and 40 $\mathrm{mg} / \mathrm{kg}$ AAPH-treated mice (Fig. 5(b)). There was no significant effect on the glutamic acid-oxaloacetic acid transaminase (GOT) or glutamic acid-pyruvic acid transaminase (GPT) levels in the serum, nor in body weight change by the treatment of MLHPO or AAPH (data not shown).

\section{DISCUSSION}

Miyazawa et al. reported that the blood plasma concentration of phosphatidylcholine hydroperoxide (PCOOH) was in the range of $10-500 \mathrm{~nm}$ in healthy humans, and at higher concentrations $(500-9,000 \mathrm{nM})$ in patients with diabetes, 

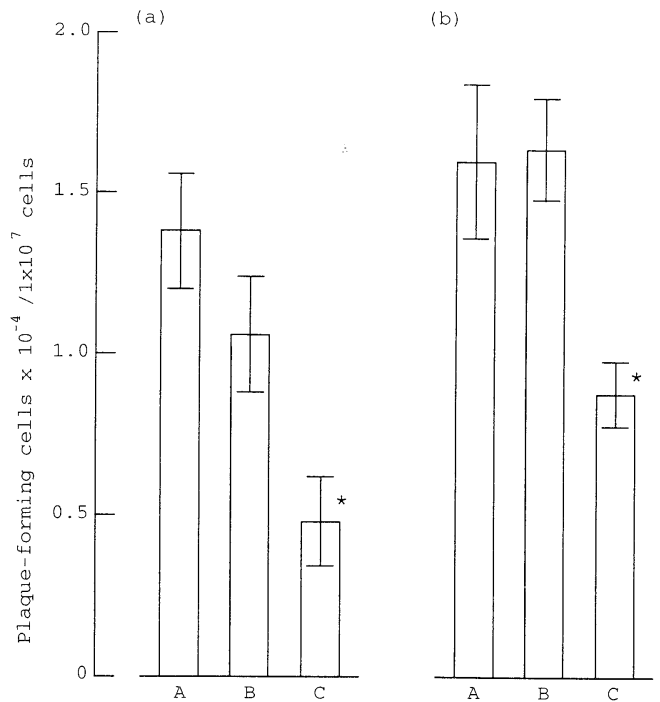

Fig. 5. Effect of MLHPO and AAPH on in vivo primary plaque-forming cell response against the SRBC of spleen cells. Mice were orally given ML or MLHPO four times at $48 \mathrm{~h}$ intervals (a) or intraperitoneally injected once with AAPH (b). (a) A, Untreated mice; B, ML-treated mice; and C, MLHPOtreated mice. (b) A, Untreated mice; B, $40 \mathrm{mg} / \mathrm{kg}$ AAPH-treated mice; and C, $60 \mathrm{mg} / \mathrm{kg}$ AAPH-treated mice. Values represent mean $\pm \mathrm{SE}$ of four mice. Significant difference from ML-treated mice (a) or untreated mice (b) was determined by Student's $t$-test $(* p<0.05)$.

liver injuries, ischemic diseases of heart and brain, or hyperlipemia depending on the progress of these diseases $(16,17)$. The concentration (mean $\pm S D$ ) for healthy young adults (22-27 years of age) was $93 \pm 17 \mathrm{pmol} \mathrm{PCOOH}$ and $121 \pm 20 \mathrm{pmol}$ phosphatidylethanolamine hydroperoxide $(\mathrm{PEOOH}) / \mathrm{mL}$ packed red blood cells, while for the aged adult (56-92 years of age) the peroxide content was significantly higher, $162 \pm 52 \mathrm{pmol} \mathrm{PCOOH}$ and $186 \pm 40 \mathrm{pmol} \mathrm{PEOOH} / \mathrm{mL}$ packed red blood cells (18). We have been investigating the effects of lipid hydroperoxides on immunocompetent cells. Since it was difficult to prepare a sufficient amount of triglyceride hydroperoxides for use in experiments, hydroperoxides of methyl linoleate have been used instead of triglycerides. When graded amounts $(8.6,12.3$ and $14.1 \mathrm{~g} / \mathrm{kg}$ ) of MLHPO were orally administered to mice, the necrosis of lymphocytes was observed in the thymus, and fatty change appeared in the liver together with an increase in the level of thiobarbituric acid reactants in the blood (7). With long-term (90 days) feeding of slightly autoxidized soybean oil (with a peroxide value of $150 \mathrm{meq} / \mathrm{kg}$ ) in mice, the DNA synthesis of thymic lymphocytes was depressed and mitogen-dependent DNA synthesis of splenic lymphoblasts was increased without an increase in the thiobarbituric acid reactant level in the blood (9). In addition, by incubation with $24.5 \mu \mathrm{M}$ MLHPO for $0.5 \mathrm{~h}$ in vitro, cyto- 
plasmic micro-organelles of mouse splenic lymphoblasts in the $S$ - and $G_{2}$-phases were markedly damaged, though no discernible damage was observed in nonblastotransformed lymphocytes (10). Taken together, these findings indicate that lipid hydroperoxides have a significant effect on blastotransformed lymphocytes in vivo. Thus, in this study, the number of developed plaque-forming cells was taken as a measure of antibody response. The results show that lipid hydroperoxides have an enhancing or depressing effect in vitro on primary antibody response, depending on the concentration. The suppression of antibody response with $50 \mu \mathrm{M}$ of MLHPO (Fig. 1) would be related to the toxic effect of MLHPO on spleen cells in the DNA synthetic phase. On the other hand, the reason for the increase in primary antibody response by the lower concentration $(2-20 \mu \mathrm{M})$ of MLHPO (Fig. 1 ) is still unclear. In addition, in vivo primary antibody response was suppressed by the oral administration of MLHPO $(2.29 \mathrm{~g} / \mathrm{kg}$, four times) (Fig. 5(a)). These results also suggest that lipid hydroperoxides could influence antibody response in vivo.

AAPH is itself stable with most compounds, and decomposes unimolecularly generating peroxy radicals at a constant and measurable rate $(12,13,19)$. It was reported that a single intraperitoneal dose of $80 \mathrm{mg} / \mathrm{kg}$ of AAPH to mice was responsible for necrosis of lymphocytes in the thymus and fatty change in the liver, although mice receiving AAPH at less than $76 \mathrm{mg} / \mathrm{kg}$ exhibited no detectable pathomorphological changes $(14,15)$. In this study, it was shown that a low concentration $(0.1 \mu \mathrm{M})$ of AAPH increased, and a high concentration $(100 \mu \mathrm{M})$ suppressed in vitro primary plaque-forming cell response (Fig. 2). The in vivo primary antibody response was suppressed by a single intraperitoneal dose of 60 $\mathrm{mg} / \mathrm{kg}$ of AAPH (Fig. 5(b)). These results suggest that peroxyl radicals derived from AAPH in vivo can exert significant effects on immunocompetent cells. In addition, El-hag and Clark reported that lymphocyte function, such as natural killer activity and mitogen-dependent DNA synthesis were suppressed by neutrophils, and this suppression was mediated by the secretion of myeloperoxidase and $\mathrm{H}_{2} \mathrm{O}_{2}$ (20).

The concentrations $(2 \mu \mathrm{M})$ of MLHPO used in the in vitro antibody response assay in this study were comparable to the blood plasma concentration range of phospholipid hydroperoxides in patients such as hyperlipemia (16). Our results suggest that lipid hydroperoxides ingested with food and/or several peroxy radicals formed endogenously could perturb the antibody response in vivo. Further studies are required to clarify what class or subclass of antibody production is affected by hydroperoxides.

\section{REFERENCES}

1) Chew BP. 1995. Antioxidant vitamins affect food animal immunity and health. J Nutr 125: $1804 \mathrm{~s}-1808 \mathrm{~s}$.

2) Lemire JM, Archer DC, Beck L, Spiegelberg HL. 1995. Immunosuppressive actions of 
1,25-dihydroxyvitamin $\mathrm{D}_{3}$ : Preferential inhibition of $\mathrm{Th}_{1}$ functions. J Nutr 125: 1704s1708 s.

3) Erickson LK, Hubbard EN, Chakrabarti R. 1995. Modulation of signal transduction in macrophages by dietary fatty acids. $J$ Nutr 125: 1683S-1686S.

4) Masawe AEJ, Muindi JM, Swai GBR. 1974. Infections in iron deficiency and other types of anaemia in the tropics. Lancet 2: 314-316.

5) Murray MJ, Murray AB, Murray MB, Murray CJ. 1978. The adverse effect of iron repletion on the course of certain infections. Br Med $J$ 2: 1113-1115.

6) Oarada M, Miyazawa T, Kaneda T. 1986. Distribution of ${ }^{14} \mathrm{C}$ after oral administration of $\left[\mathrm{U}-{ }^{14} \mathrm{C}\right]$-labeled methyl linoleate hydroperoxides and secondary oxidation products in rats. Lipids 21: $150-154$.

7) Oarada M, Ito E, Terao K, Miyazawa T, Fujimoto K, Kaneda T. 1988. The effect of dietary lipid hydroperoxide on lymphoid tissues in mice. Biochim Biophys Acta 960: 229-235.

8) Oarada M, Miyazawa T, Fujimoto K, Ito E, Terao K, Kaneda K. 1988. Degeneration of lymphoid tissues in mice with the oral intake of low molecular weight compounds formed during oil autoxidation. Agric Biol Chem 52(8): 2101-2102.

9) Oarada M, Majima T, Miyazawa T, Fujimoto K, Kaneda T. 1989. The effect of dietary autoxidized oils on immunocompetent cells in mice. Biochim Biophys Acta 1012: $156-160$.

10) Oarada M, Terao K. 1992. Injury of mouse lymphocytes caused by exogenous methyl linoleate hydroperoxides in vitro. Biochim Biophys Acta 1165: 135-140.

11) Cunningham AJ. 1965. A method of increased sensitivity for detecting single antibody-forming cells. Nature 207: 1106-1107.

12) Yamamoto Y, Niki E, Kamiya Y, Shimasaki H. 1985. Oxidation of biological membranes and its inhibition: Free radical chain oxidation of erythrocyte ghost membranes by oxygen. Biochim Biophys Acta 819: 29-36.

13) Niki E, Kawakami Y, Yamamoto Y, Kamiya Y. 1985. Oxidation of lipids: 8. Synergistic inhibition of oxidation of phosphatidylcholine liposome in aqueous dispersion by vitamin E and vitamin C. Bull Chem Soc Jpn 58: 1971-1975.

14) Terao K, Niki E. 1986. Damage to biological tissues induced by radical initiator $2,2^{\prime}$ azobis (2-amidinopropane) dihydrochloride and its inhibition by chain-breaking antioxidants. Free Radical Biol Med 2: 193-201.

15) Terao K. 1989. Liver injuries induced by free radicals. J Toxicol Pathol 2: 11-18.

16) Miyazawa T, Yasuda K, Fujimoto K, Kaneda T. 1988. Presence of phosphatidylcholine hydroperoxide in human plasma. $J$ Biochem 103: 744-746.

17) Miyazawa T. 1989. Determination of phospholipid hydroperoxides in human blood plasma by chemiluminescence-HPLC assay. Free Radical Biol Med 7: 209-217.

18) Miyazawa T, Suzuki T, Fujimoto K, Kinoshita M. 1996. Age-related change of phosphatidylcholine hydroperoxide and phosphatidylethanolamine hydroperoxide levels in normal human red blood cells. Mech Ageing Devel 86: 145-150.

19) Niki E, Saito T, Kawakami A, Kamiya Y. 1984. Inhibition of oxidation of methyl linoleate in solution by vitamin E and vitamin C. J Biol Chem 259: 4177-4182.

20) El-hag A, Clark RA. 1987. Immunosuppression by activated human neutrophils. $J$ Immunol 139: 2406-2413. 